\title{
ANALYSIS OF THE FINANCIAL SITUATION OF MEDIUM-SIZED AND LARGE ENTERPRISES OF THE CONSTRUCTION SECTOR IN SELECTED CENTRAL EUROPEAN COUTRIES
}

\author{
Rafał Wolski, PhD. \\ Department of Economics of Industry and Capital Markets \\ Faculty of Economics and Sociology \\ University of Lodz \\ email:rwolski@uni.lodz.pl
}

\author{
Magdalena Załęczna, PhD. \\ Department of Investment and Real Estate \\ Faculty of Economics and Sociology \\ University of Lodz \\ email:mzaleczna@uni.lodz.pl
}

\begin{abstract}
The economy is subject to periodic changes in activity, which is apparent in the financial situation of households and enterprises. However, the recent economic crisis has been particularly severe. After the great increase in economic activity, which in many countries was connected with the boom in the real estate market, it experienced a sudden turn for the worse, including the broadly understood construction sector. This contributed to a slowdown of the growth rate, or even a permanent economic downturn. The authors have undertaken an analysis of the situation in the construction sector and the condition of residential real estate markets in selected Central European countries, and next, on the basis of a database on the financial situation of selected construction companies constructing buildings in those countries, searched for an answer to the question of how much the construction sector and the analyzed enterprises changed their activity in the recent years. For the purpose of the analysis, a database of over 340 entities from the Czech Republic, Poland, Slovakia and Hungary was created. The work is of a comparative nature, which allows the scale of the processes studied in the individual countries to be identified.
\end{abstract}

Key words: construction companies, residential real estate, profitability, Central Europe.

JEL Classification: D22, L25, R30.

Citation: Wolski R., Załęczna M., 2014, Analysis of financial situation of medium-size and large enterprises of the construction sector in selected central European countries, Real Estate Management and Valuation, vol. 22, no. 3, s. 73-84.

DOI: $10.2478 /$ remav-2014-0029

\section{Introduction}

Economic revival and the boom in the real estate market in the years 2000-2008 were strictly related. In some countries, the increased activity of the construction sector, greatly involved in the residential market, played an important role in those processes. These countries included: Ireland, Spain and Cyprus, and among the post-socialist countries - the Baltic States and Croatia (SUN, MITRA, SIMONE 2013). Analyzing the collective data, it should be noted that on the eve of the crisis, in 2007, the construction sector of the EU member countries provided employment to 14.8 million employees 
(11.5\% people employed in non-financial sectors) and provided EUR 562 billion in value added (9.3\% of total value added of non-financial sectors). However, after the period of revival, construction activity died down due to the economic crisis. In individual EU Member States, the problems of the construction sector were particularly apparent among other things in Spain, the Baltic States or in Ireland. The knock-on effect in the form of a significant reduction of employment in the construction sector, bankruptcies of developers, and decreased employment in banks due to the significant reduction of granted loans, further increased economic problems (STAWINSKA 2010).

On the scale of the entire EU, the data do not present as negative an image as in the countries which are most dependent on the situation in the construction sector. In 2010, employment in the construction sector in countries of the EU amounted to 13.4 million (10\% of people employed in nonfinancial sectors), and the value added generated by this sector amounted to EUR 496 billion $(8.4 \%$ of the total value added generated by non-financial sectors). Between January 2008 and February 2010, the construction output index decreased by $13.4 \%$; in the following years the situation did not improve, decreasing by $18.1 \%$ in the period between February 2008 and June 2012 (Construction Statistics, Eurostat 2013).

The largest part of the sector, i.e. concerning the construction of buildings, clearly felt the effects of the crisis - the comparison of the beginning of 2007 and 2010 indicates a drop in activity of $16.5 \%$. The only country which did not show a decrease was Poland, whereas the Czech Republic and Italy suffered the effects of the construction sector crisis between the years 2008 and 2011, Spain and Ireland between 2007 and 2011, and Hungary between 2006 and 2011. The length of the period of decreased activity is influenced by local economic and social factors; in the case of some countries, including Greece, Ireland, Latvia, Lithuania and Hungary, a quick revival has been anticipated, whereas others, such as Spain, the United Kingdom, Romania or Slovakia, will probably experience problems in the construction sector for longer (SUN, MITRA, SIMONE 2013).

The authors analyzed changes of the economic situation in the construction sector and the residential market in the Czech Republic, Poland, Slovakia and Hungary. The purpose of the research was to find an answer to the following question: based on data regarding the financial situation of selected construction companies dealing with the construction of buildings, how much has the activity of the construction sector and analyzed entities changed in the recent years in the four Central European states.

\section{Condition of the construction sector in the studied countries}

Post-socialist states which acceded the EU in 2004 have the status of "catching-up" countries. The level of their economic development is lower than the EU average, therefore growth should be more intense. Special funds provided under various aid schemes are used for this purpose, some of them being used to create new infrastructure and involving the construction sector. Therefore, it may be said that from this point of view, the construction sector will continue to take on new tasks in the analyzed countries even after a significant reduction of activity in the real estate market. The assessment of the relationship between the economic situation and the condition of the construction sector has been based on several ratios in the surveyed period: share of the sector in the generation of GDP, number and structure of construction companies, value of construction output, and number of employees.

The analysis of the share of the construction sector in the generation of GDP in the countries covered by the study in the years 2007, 2009 and 2012 allows us to conclude that Poland is the only country in which this sector strengthened its position - cf. figure 1 . The scale of changes should be noted - in Poland the increase was from $9.2 \%$ to $12.5 \%$ (after an initial drop to $6.1 \%$ in 2009). In the Czech Republic, the share of the construction sector in the GDP dropped to $11.1 \%$ from $14.5 \%$. The relevance of the construction sector also decreased in Slovakia - from $9.1 \%$ to $6.6 \%$, and in Hungary from $11.8 \%$ to $5.6 \%$.

The specificity of the structure of the construction sector in the countries under study is the fact that a great majority of enterprises in this sector are small entities, employing up to 9 persons - see figures 2 , 3,4 and 5. Slovakia stands out among the analyzed countries, as it has noted a huge increase in the number of construction companies since 2010, which, however, has been distorted by the change in the method of counting construction companies which took place at the level of domestic statistics. 


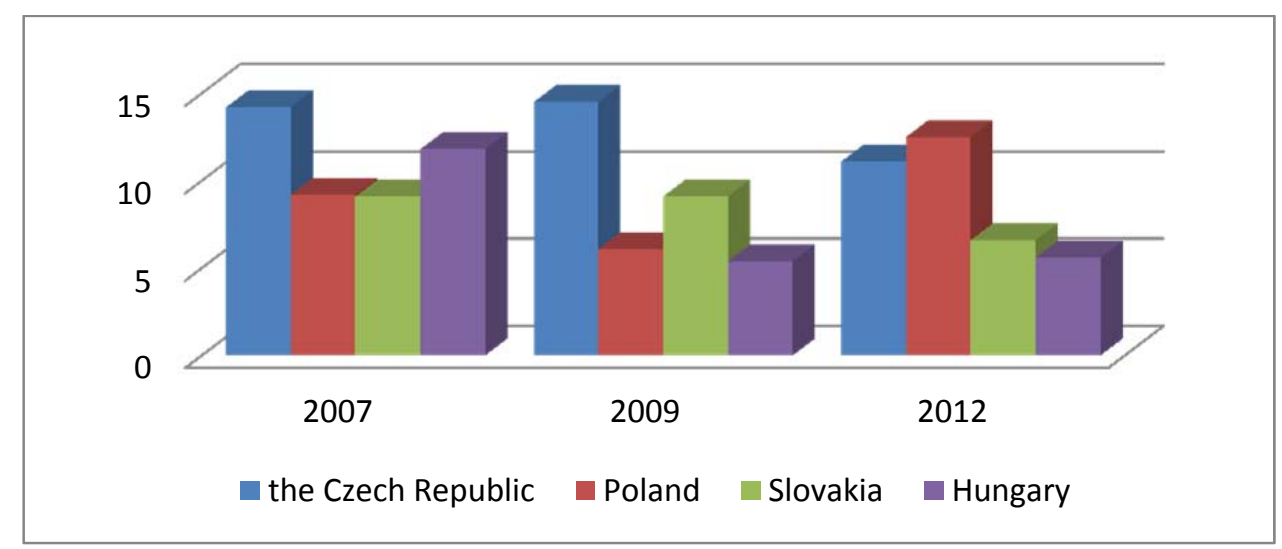

Fig. 1. Share of the construction sector in the generation of GDP in selected countries (\%). Source: own study based on data from the European Construction Industry Federation.

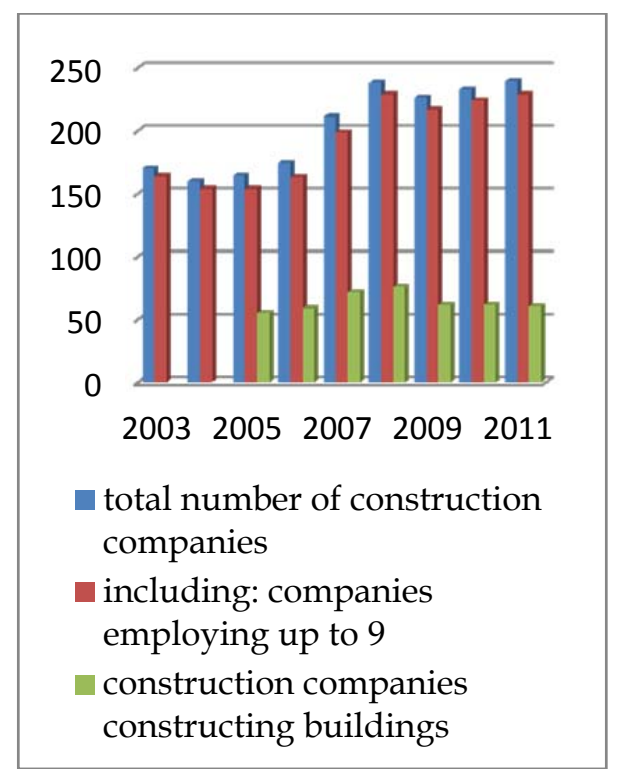

Fig. 2. Number and structure of construction companies in Poland (in thousands)

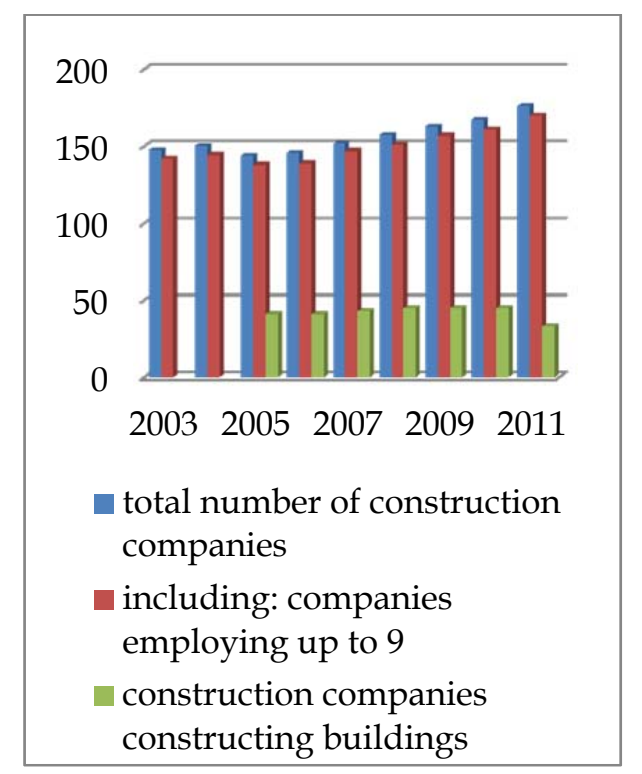

Fig. 3. Number and structure of construction companies in the Czech Republic (in thousands)

Source: own study based on Eurostat data.

The study of the structure of construction companies may indicate that, in the earlier years, the proportion of the smallest entities employing up to 9 persons in Hungary was not as high, whereas over $95 \%$ of the construction companies in both the Czech Republic and in Poland were small.

When analyzing the changes in the number of construction companies in the years 2003-2011 (last available comparable data), it should be noted that a tendency for the number of construction companies to decrease after 2008 occurred only in Hungary. In the Czech Republic their number increased, and in Poland, after a one-year drop, the number of construction companies increased again in 2010 and 2011. A different situation may be observed with regard to a narrower category of entities - constructing mainly buildings. In the Czech Republic their number decreased noticeably in 2011, and in Poland in 2009, similarly as in Hungary (the decrease there was also in 2010).

Changes in the number of enterprises do not coincide with the picture obtained from the analysis of the number of people employed in the construction sector. An increasing tendency could be observed until 2007, though characterized by different levels in the individual analyzed countries, with Poland standing out significantly (cf. figure 6). Starting in 2008, there was a reduction in employment; the Polish construction sector was least effected, whereas the reaction in Hungary was the strongest, with employment in the construction sector falling almost $20 \%$ in 2009. 


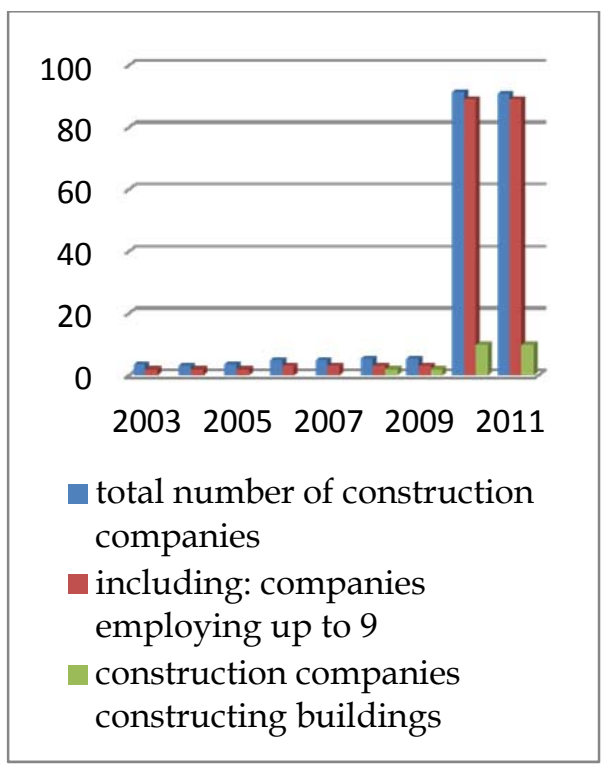

Fig. 4. Number and structure of construction companies in Slovakia (in thousands)

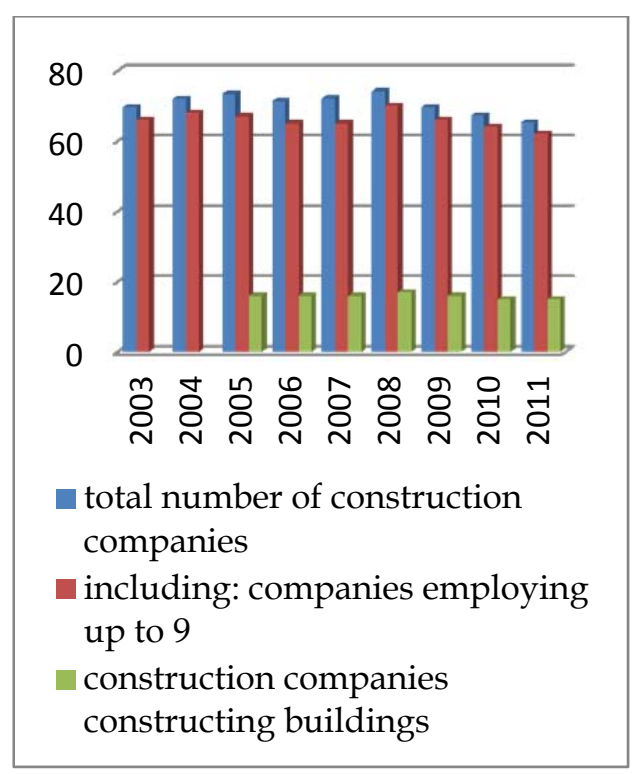

Fig.5. Number and structure of construction companies in Hungary (in thousands)

\section{Source: own study based on Eurostat data.}

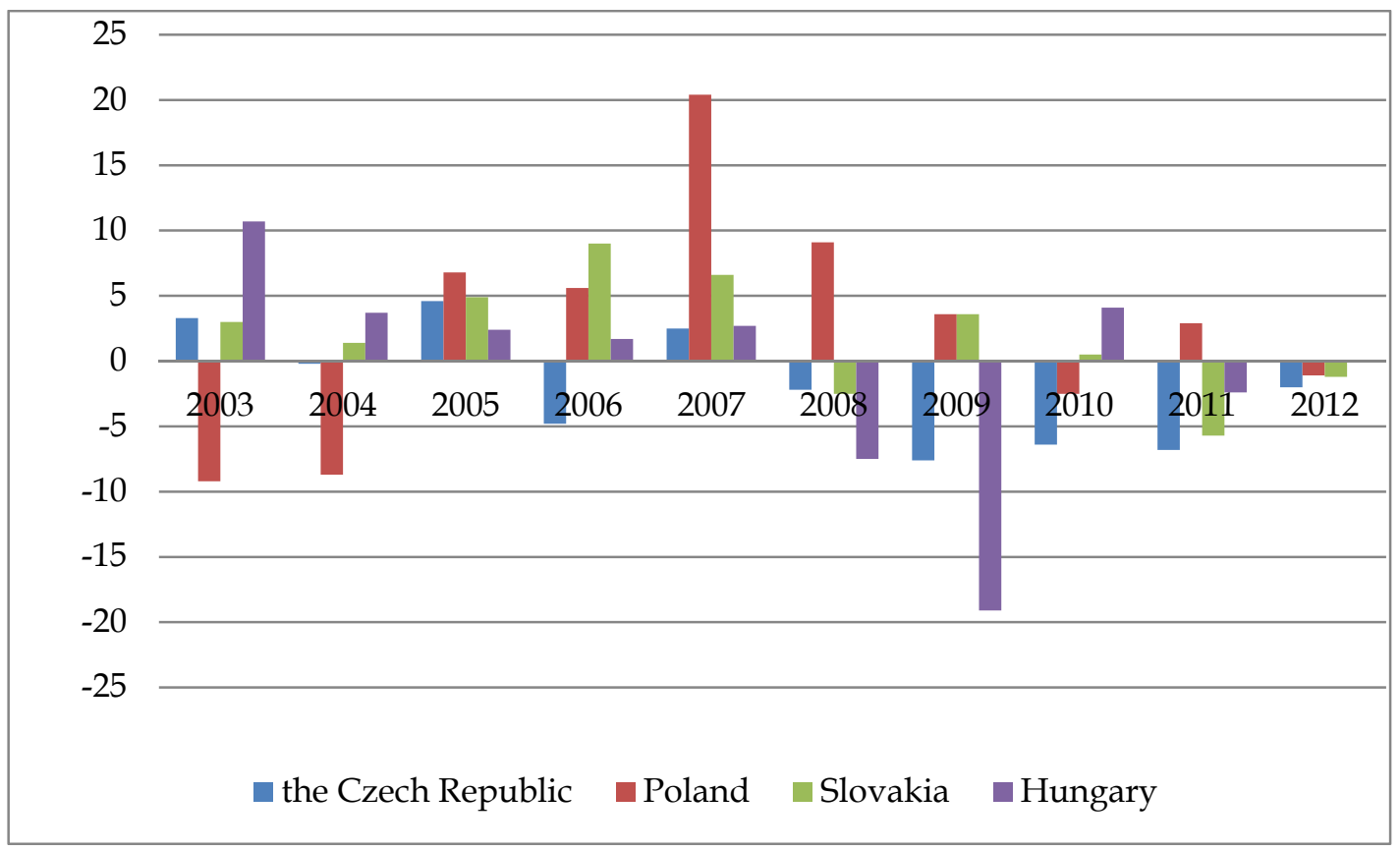

Fig. 6. Changes in the level of employment in the analyzed countries in the years 2003-2012 (\%). Source: own study based on data from the European Construction Industry Federation.

The impact of the economic downturn was apparent in the value of construction output, however to different degrees. The analysis of national data allows two countries in which the year 2008 was a peak year in terms of the value of construction output to be identified - namely the Czech Republic and Hungary (cf. figure 7). In the Czech Republic a drop in the value of construction output was observed in 2009, but it did not continue into the following years. The situation was different in Hungary, where a downward trend was clearly visible.

In Slovakia, a single drop in the value of construction output in 2009 was followed by an increase in 2010 and next - stabilization. In the case of Poland, an increase was recorded in the years following an initial reduction in the value of construction output in 2009. When analyzing data in more detail and referring to the value of output with regard to the construction of buildings, it should be noted that in the Czech Republic and in Hungary this part of the construction sector reflected general 
tendencies. In Slovakia, however, no increase in construction output with regard to the construction of buildings was observed despite the upward trend observed in the activity of the entire sector. In Poland, the increase of the value of construction output with regard to the construction of buildings was very slight.

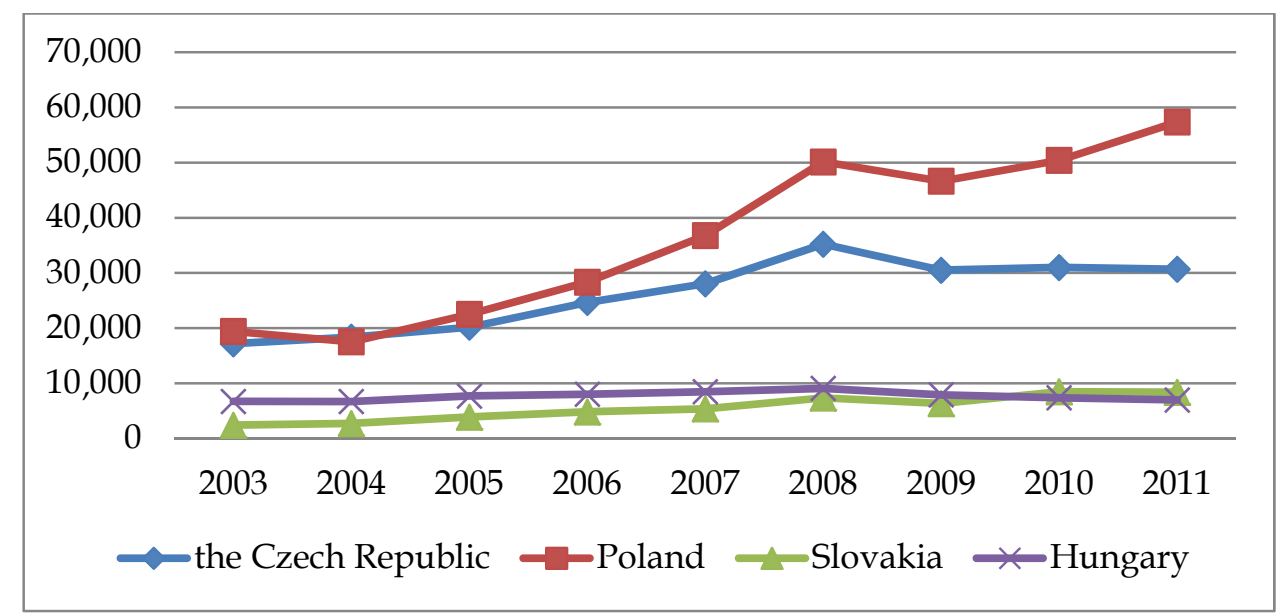

Fig. 7. Value of construction output in the analyzed countries in the years 2003-2011 (EUR million). Source: own study based on Eurostat data.

\section{Situation in residential real estate markets in the analyzed countries}

Real estate markets in post-socialist states were formed thanks to the new institutional framework, which resulted from the political and economic transformation at the national level. However, the economic situation on real estate markets depends both on global factors and on local ones, factors which are external in relation to real estate markets, and those resulting from their very nature (EGERT, MiHALJEK 2007; LEAMER 2007; GIROUARD et al. 2006). Housing markets have started to be perceived globally as an area for investments (TSATSARONIS, HAIBIN 2004; BEBLAVY, COBHAM, OdOR 2011). On the rising tide of interest in investments in residential properties, some states experienced a boom in construction which was reflected in the labor market and in the economy in general; such countries included Spain and Ireland. The increase in demand and the postponed supply was reflected in the increase in prices, which upheld the conviction that investments in the housing market were profitable (DOKKO et al. 2011).

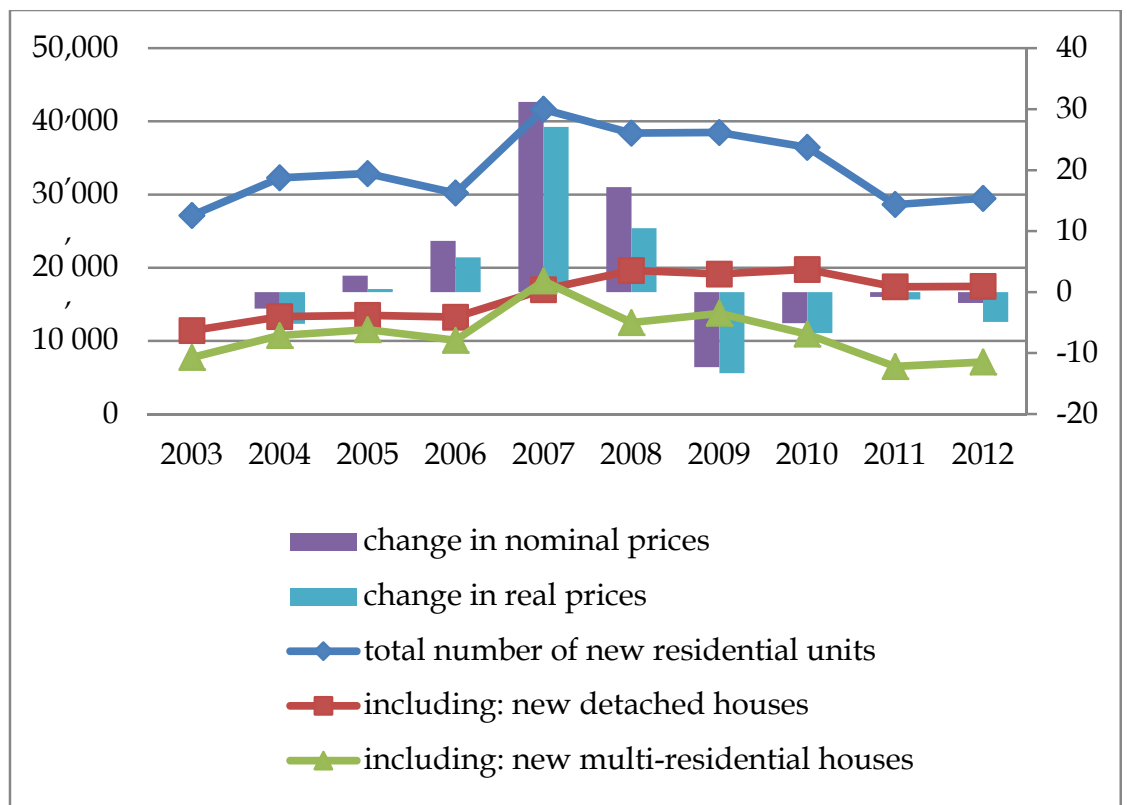

Fig. 8. Residential units completed and price changes on the housing market (\%) in the years 20032012 in the Czech Republic. Source: own study based on CSO data and data from the Central Bank in the Czech Republic. 
The analyzed post-socialist countries experienced a revival in the area of housing construction; however, an analysis of the numbers of residential units completed did not indicate a boom. In the Czech Republic in 2003, 27,000 residential units were completed, of which 7,700 in multi-residential buildings. The peak period fell in 2007, when the construction of over 41,000 residential units was completed, 17,000 of which were in multi-residential buildings. The revival lasted another three years (which was probably the consequence of the completion of previously started investments), and the effects of the downturn were clearly visible in 2011 when 28,600 residential units were handed over for occupation, including 6,500 in multi-residential buildings - cf. figure 8 .

Changes in the residential real estate market indicate a peak in 2007, when prices increased on average by $30 \%$, and the most significant decrease in 2009 , from which the market did not rebound in the following years - cf. figure 8 .

In Poland, after 2003, when the number of residential units completed was artificial (new legal regulation), a stable growth of new residential units could be observed, peaking in 2008 when 165,000 residential units were completed-cf. figure 9. In the years 2010 and 2011, a downwards trend could be observed, which was reversed in 2012. The segment of flats constructed by developers had a significant share in the revival of the primary residential market, which had also experienced an economic slowdown and changes in the prices of housing units.

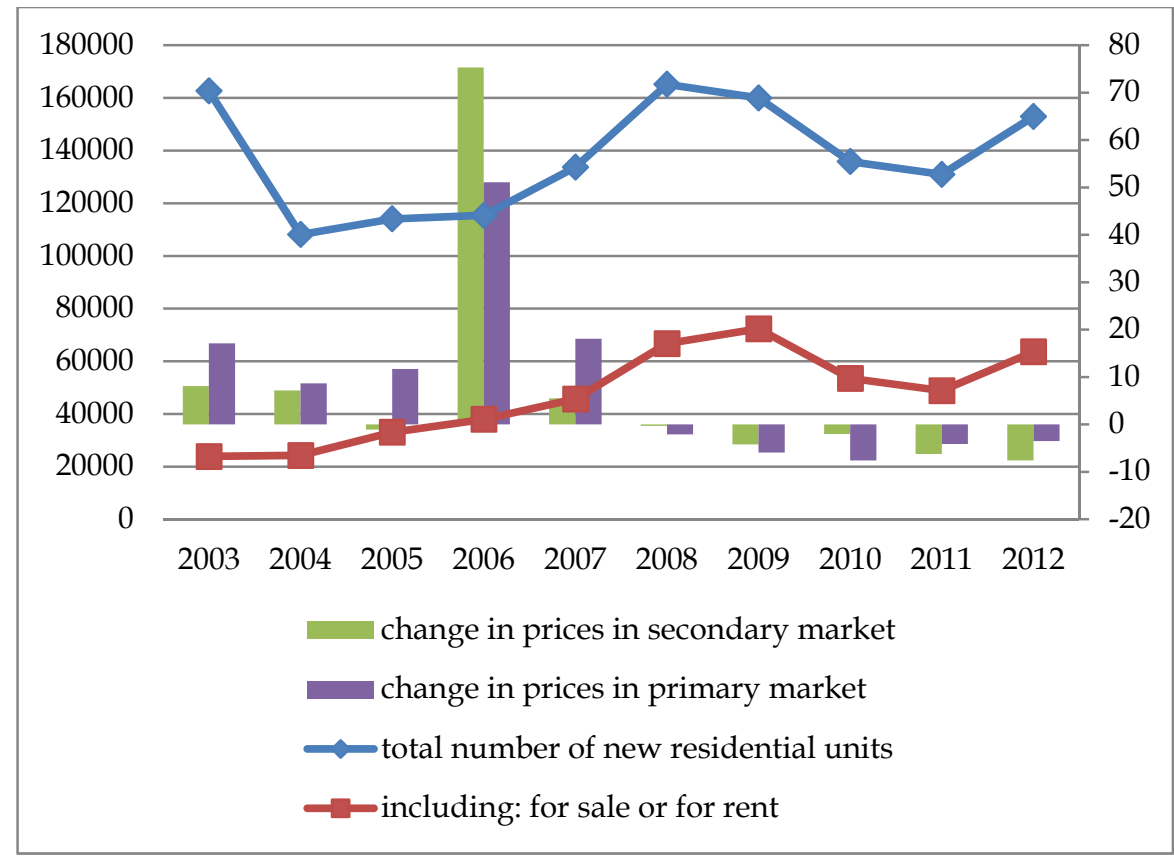

Fig. 9. residential units completed and changes in prices in the housing market (\%) in the years 20032012 in Poland. Source: own study based on CSO data and data from the Central Bank in Poland.

The analysis of changes in prices in the residential real estate market in Poland clearly points to the year 2006 as the time of the most dynamic increases - cf. figure 9. The drops in prices in the following years were not huge, however they did show the traits of a lasting trend, which probably affected the investment decisions made.

The moderate activity during the analyzed period on the primary housing market was also observed in Slovakia. Here, there was also an initial increase in the number of residential units completed, which peaked in 2009 when almost 19,000 flats and houses were delivered, as compared to 2003, when the number was 14,000. In the following years, a smaller number of residential units were handed over for occupation, but the level of 14,000-15,000 was maintained - cf. figure 10.

Changes in the prices of residential units indicate moderate increases during the revival period, though their scale depends on the type of housing - cf. figure 10. Decreases in prices were most noticeable in 2009, with the following years characterized by a period of stagnation.

Only in Hungary could a tendency towards the permanent reduction of activity in the primary residential market be observed. Moreover, the period of the highest activity was clearly visible in the years 2004-2005, when over 40,000 flats and houses were completed each year - cf. figure 11. In the 
years 2006-2009, over 30,000 residential units a year were completed, whereas construction activity in the subsequent years decreased more significantly, with only 10,500 residential units completed in the year 2012. Developers also notably decreased the number of residential units completed from over 18,000 in 2005 to just 3,000 in 2012.

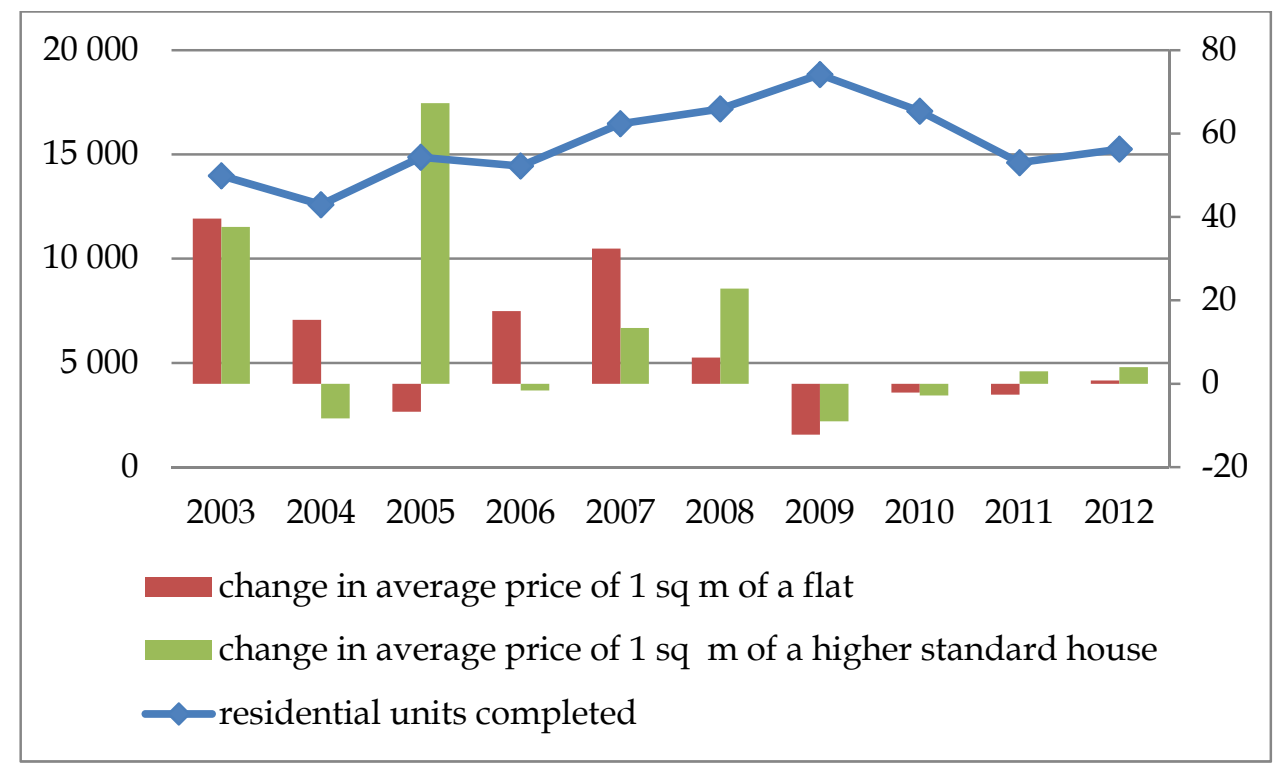

Fig. 10. Residential units completed and changes in prices in the housing market (\%) in the years 20032012 in Slovakia. Source: own study based on CSO data and data from the Central Bank of Slovakia.

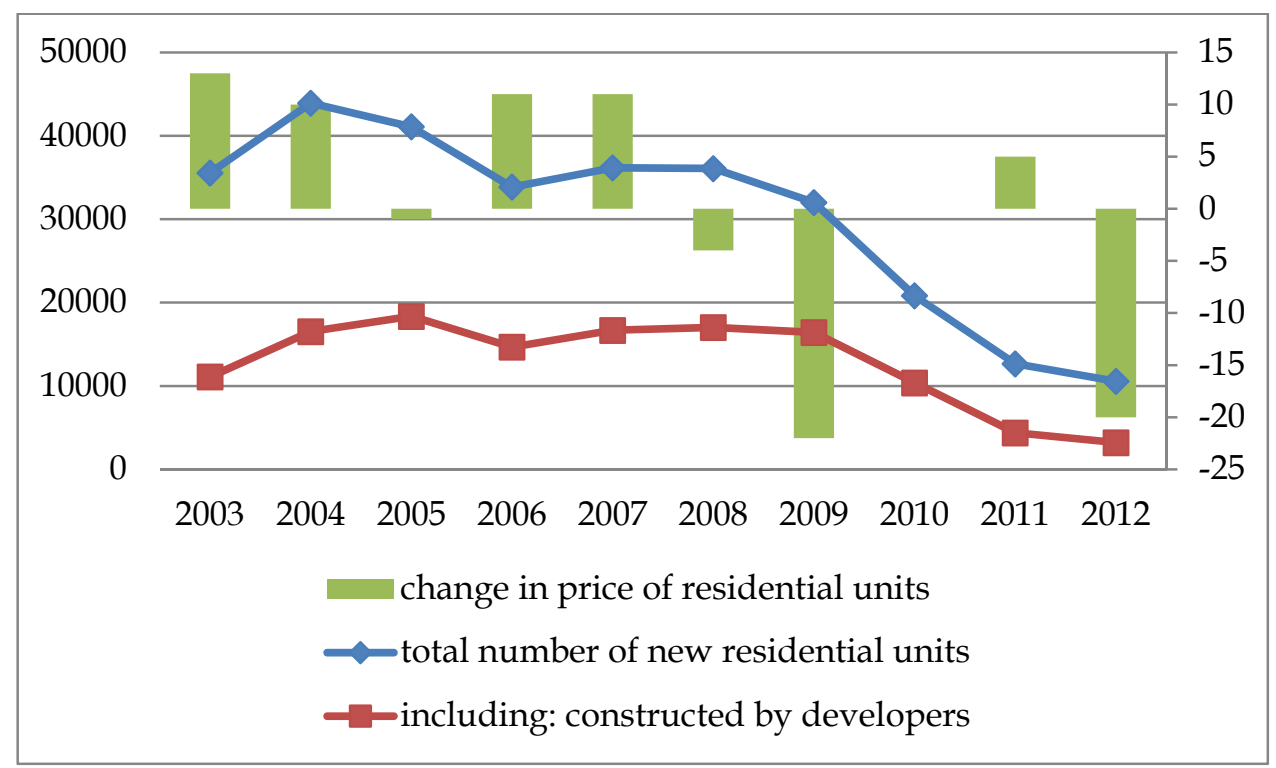

Fig. 11. New residential units handed over for occupation and changes in prices in the housing market (\%) in the years 2003-2012 in Hungary. Source: own study based on CSO data and data from the Central Bank of Hungary.

Changes in prices in the Hungarian market are not similar to those described earlier. Strong decreases were recorded in 2009, and continued into 2012. The analysis can lead to the conclusion that that this market most reflected the severe economic problems of its country.

The study of the construction sector and the situation in the residential real estate market allow us to formulate a statement that the country which stands out due to the development of its construction sector and the stability of its housing market is Poland. On the contrary, the country in which both the construction sector and the residential market are experiencing severe problems is Hungary. 


\section{Study of selected companies}

A database of companies from the construction sector constructing mainly buildings was used in the study. The database consisted of 342 entities, including 63 companies from the Czech Republic, 190 from Poland, 16 from Slovakia, and 73 from Hungary. The study period covered the years 2003 to 2012, or 2004 to 2012. All financial data originated from the Amadeus database. Data on GDP in market prices, expressed in EUR, was taken from the Eurostat database, and data concerning stock exchange indexes are derived from stock exchanges in Prague, Budapest, Warsaw and Bratislava. In the case of selected ratios, year-on-year changes were calculated. These ratios included: total assets, EBIT, and net profit. All enterprises were a part of the sector denoted in the Amadeus database as "primary code: 41 - Construction of buildings." Additionally, in the filtering of companies, a criterion was selected based on which only very large and large entities were taken into consideration. Due to the structure of the database on construction companies, it should be indicated that there is a significant difference between collective statistical data at the level of the country, and data obtained from the database covered by the study. This is due to the fact that the data on individual enterprises are collected at the level of large and very large entities, whereas a significant majority of enterprises in the construction sector employ up to 9 persons.

In the case of the Czech Republic, 20 correlation coefficients out of 52 results had relatively high values exceeding $-/+0.5$, whereas 11 of those 20 coefficients were statistically significant. The authors assumed that a high correlation coefficient, regardless of whether it is positive or negative, suggests an impact of the market downturn on enterprises connected with the construction industry. However, in the light of the results obtained, it may be considered doubtful whether this impact was strong in the Czech Republic. Of the statistically significant correlation coefficients, the strong positive correlation of the level of GDP and the cash flow CF, total assets, EBIT and net profit is worth noting.

Table 1

Pearson correlations between selected effectiveness ratios of Czech enterprises and basic ratios describing the economic situation.

\begin{tabular}{l}
\hline \\
\hline
\end{tabular}

Source: own study.

The economic situation in the Czech Republic is therefore reflected positively in the affluence of enterprises measured by the level of their assets and profits. However, the strong negative correlation of GDP with ROE suggests that profitability decreases together with economic growth. Although the first impression may suggest that this relationship constitutes a certain distortion of observations, if we look at the company finances, the situation of the country and profitability from the point of view 
of the investment process, it is worth considering whether the mechanism of this situation is not as follows: the increase of company resources, correlated with the increase of the affluence of the country, promotes investment processes, with the latter reducing the profitability of the enterprise.

In the case of the stock exchange index, only EBIT was strongly positively correlated with PXGLOB. Based on the assumptions of the fundamental analysis, this phenomenon may be interpreted as an improvement of the market situation as a result of the growing profits of enterprises. However, because other profitability ratios are not correlated at a statistically significant level, this conclusion should be deemed only a speculation and possible introduction to further deliberations.

The other two countries seem to present a different pattern of responses of companies to economic turbulences. Both in the case of Poland and Slovakia, a strong correlation between total assets and country GDP may be observed. For Poland, this coefficient is at $p=0.94$ and is statistically significant at the confidence level of $99 \%$. In this case, other coefficients are quite high as well. Out of 52 results, 21 are above 0.5 or below -0.5 . Out of these, 11 coefficients are statistically significant at the level of 0.05 and 0.01 .

Table 2

Pearson correlations between selected effectiveness ratios of Polish enterprises and basic ratios describing the economic situation.

\begin{tabular}{l}
\hline \\
\end{tabular}

Source: own study.

The analysis conducted revealed statistically significant, high correlation coefficients between the value of the stock exchange index, in this case WIG, and cash flow CF, EBIT, net profit, current ratio $\mathrm{CR}$ and profit margin. It may thus be assumed that the market responds to the situation of enterprises with relevant prices changes. This way the improvement of the financial standing of a company is reflected in the improved market situation. Similar correlations have been shown in the case of Poland's GDP. Not only do total assets go up together with the growth of GDP (as had already been mentioned), but so do cash flow, solvency ratio, EBIT and current ratio. The statistically significant correlations between GDP and the change of EBIT and net profit do not allow for a logical interpretation. The correlations between the change of GDP and the change of ratios of enterprises should be subject to interpretation, but in this case, these were statistically insignificant and relatively weak. In the case of Slovakia, 14 strong (below -0.5 or above 0.5 ) correlation coefficients were noted, however only 8 of them were statistically significant. 
Table 3

Pearson correlations between selected effectiveness ratios of Slovak enterprises and basic ratios describing the economic situation.

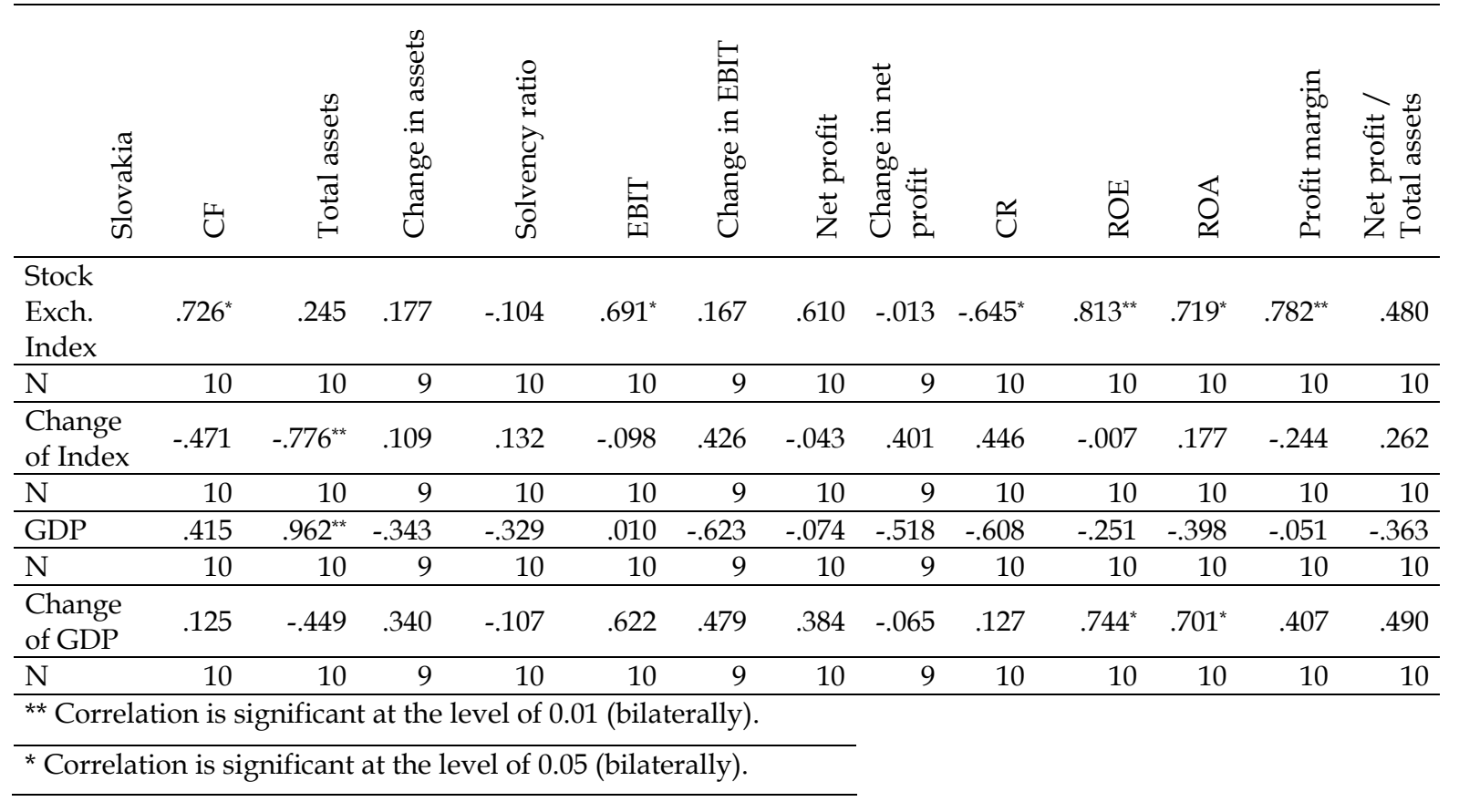

Source: own study.

Table 4

Pearson correlations between selected effectiveness ratios of Hungarian enterprises and basic ratios describing the economic situation.

\begin{tabular}{|c|c|c|c|c|c|c|c|c|c|c|c|c|c|}
\hline 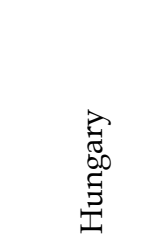 & 岂 & $\begin{array}{l}\text { 足 } \\
0 \\
0 \\
0 \\
\frac{\pi}{\pi} \\
0 \\
0\end{array}$ & 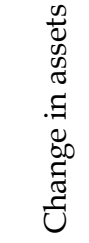 & 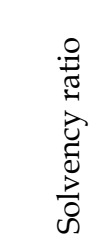 & 竞 & 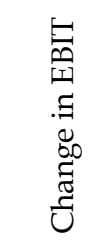 & 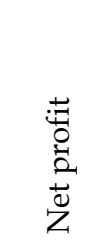 & 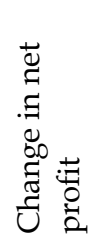 & 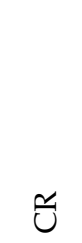 & 留 & 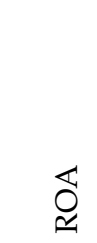 & 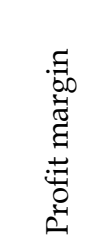 & 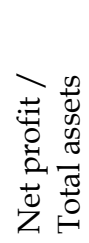 \\
\hline $\begin{array}{l}\text { Stock } \\
\text { Exch. } \\
\text { Index }\end{array}$ & .481 & .496 & -.113 & -.524 & .399 & -.208 & .071 & -.083 & .064 & -.518 & -.608 & -.073 & -.615 \\
\hline $\mathrm{N}$ & 10 & 10 & 9 & 10 & 10 & 9 & 10 & 9 & 10 & 10 & 10 & 10 & 10 \\
\hline $\begin{array}{l}\text { Change of } \\
\text { Index }\end{array}$ & -.286 & -.314 & .381 & .313 & -.231 & .320 & -.098 & -.043 & .040 & .277 & .258 & -.051 & .283 \\
\hline $\mathrm{N}$ & 10 & 10 & 9 & 10 & 10 & 9 & 10 & 9 & 10 & 10 & 10 & 10 & 10 \\
\hline GDP & .579 & $.722^{*}$ & -.299 & $-.712^{\star}$ & .441 & -.250 & .221 & .038 & .063 & $-.678^{*}$ & $-.743^{*}$ & -.052 & $-.756^{*}$ \\
\hline $\mathrm{N}$ & 10 & 10 & 9 & 10 & 10 & 9 & 10 & 9 & 10 & 10 & 10 & 10 & 10 \\
\hline $\begin{array}{l}\text { Change of } \\
\text { GDP }\end{array}$ & -.150 & -.516 & .307 & .436 & -.460 & -.176 & -.295 & -.289 & .446 & .163 & .273 & -.127 & .140 \\
\hline $\mathrm{N}$ & 10 & 10 & 9 & 10 & 10 & 9 & 10 & 9 & 10 & 10 & 10 & 10 & 10 \\
\hline
\end{tabular}

Source: own study.

The correlation coefficients concerning the value of the stock exchange index (in Slovakia this index is SAX) were statistically significant for correlations with cash flow CF, EBIT, current ratio CR, ROE and ROA interest rates, and profit margin. All these correlations were positive, with the exception of the correlation between the value of the SAX index and current ratio CR. Other statistically significant 
correlations were noted for correlation coefficients for GDP and total assets, as well as for the change of GDP year-on-year and ROE and ROA interest rates.

In the case of Hungary, 11 ratios were correlated with market ratios more strongly than $p=0.5$ or $\mathrm{p}=-0.5$. Of these 11 correlations, only 5 were statistically significant. When attempting to analyze the observed correlations, one might mention the highly statistically significant correlation between total assets and GDP. This means that the level of GDP strongly reflected the affluence of economic operators. What is interesting, however, is that together with an increase in GDP, the solvency ratio experienced a statistically significant decrease. If we combine this with the statistically significant, relatively high negative correlation coefficients for GDP with ROE an ROA, a claim may be risked that enterprises undertake investment processes. In the case of Hungary, similarly to the Czech Republic, the lack of strong correlations between statistics describing the condition of the economy and ratios describing the condition of enterprises connected with the construction sector may suggest that the economic crisis did not strongly affect the situation of enterprises. This suggests a relatively smooth passage of economic operators through macroeconomic turbulences. The fact that the level of assets follows Slovakia's GDP, and that the positive correlation of the rates of return on equity and on assets together with changes in GDP are visible, allow a cautious conclusion that the economic situation of the country influenced the situation of enterprises in the construction sector.

Poland's and Slovakia's GDP slowed down considerably after 2009, which suggests maybe not as much a crisis, as an economic slowdown. In this context, the fact that ratios describing the profitability and earnings of enterprises are correlated with the country's GDP also suggests a slowdown in the construction sector. However, looking at the level of total assets, it is difficult to talk about an actual crisis. In turn, the drop in net profits, observed mainly in Poland and Slovakia, may suggest problems experienced by the sector.

After analyzing the situation of medium-sized and large enterprises in the construction sector, the authors found that in the Czech Republic and Hungary the analyzed enterprises coped quite well with the economic downturn, whereas in Poland and Slovakia, a decrease in the average profit of enterprises, measured by a median, could be observed. The drop in profit, however, was not accompanied by a decrease in the level of total assets.

\section{Conclusions}

A specific database of medium and large-sized construction companies, the core activity of which was the construction of buildings, was used against the background of the economic situation in the construction sectors and the residential real estate markets of the analyzed countries. In the light of the data on the situation in the construction sector and the housing market, Poland appears to be the leader, whereas Hungary is a country where the sector covered by the study is going through difficulties. The analysis of data about the situation in specific enterprises provided additional knowledge and enabled the authors to draw conclusions concerning large and very large construction companies involved in the construction of buildings. In view of this analysis, large Hungarian enterprises are not found to be experiencing a downturn. The fact that enterprises whose situation was quite good survived the market downturn enables the authors to see the potential for the revival of activity in the sector. A stable base will constitute a good start for entities involved in the construction of buildings.

\section{References}

Beblavy M., Cobham D., Odor L. (ed). (2011): The Euro Area and the Financial Crisis. Cambridge University Press.

Construction Statistics, Eurostat 2013.

DOKKO J., Doyle B., Kiley M.T.,, Kim J., Sherlund S., Sim J., VAn Den Heuvel S. (2011). Monetary Policy and the Global Housing Bubble, Economic Policy 66, 237-287.

ÉGERT B., MiHAlJEK D. (2007). Determinants of house prices in Central and Eastern Europe, CESifo working paper, No. 2152.

European Construction Industry Federation Report 2006, 2008, 2010, 2012.

GiROUARD N., KENNEDY M., VAN DEN NOORD P., Christophe A. (2006): Recent house price developments: the role of fundamentals", OECD Economics Department Working Paper No. 475, January. 
LEAMER E., (2007). Housing is the business cycle, NBER working paper series; 13428, Cambridge Mass.: National Bureau of Economic Research.

STAWINSKA A., (2010). The EU-27 construction sector: from boom to gloom, Statistics in focus 7/2010, Eurostat.

Sun Y, Mitra P., SIMONE A.,(2013). The Driving Force behind the Boom and Bust in Construction in Europe, IMF Working Paper WP 13/181.

TSATSARONIS K., HAIBIN Z. (2004). What drives housing price dynamics: cross country evidence, BIS Quarterly Review, March. 